\title{
A pulsão de morte segundo Max Horkheimer: discussões sobre emancipação e repressão social nos anos 1930 e $1940^{1}$
}

\author{
The death drive according to Max Horkheimer: discussions on social \\ emancipation and repression in the 1930s and $1940 \mathrm{~s}$
}

\section{Simone Bernardete Fernandes ${ }^{*}$}

\begin{abstract}
Resumo: Nos anos 1930 e 1940, Max Horkheimer investigou as origens da agressividade manifesta na vida social, sobretudo na forma do antissemitismo. Suas referências ao conceito de pulsão de morte divergem nestes contextos, uma distinção que se relaciona estreitamente a mudanças consideráveis em sua filosofia. A princípio, este conceito é preterido por reproduzir uma concepção ideológica que justifica e hipostasia o vínculo da civilização com a repressão pulsional, vínculo supostamente necessário em vista da ameaça de suas manifestações destrutivas para a vida em sociedade. Posteriormente, no entanto, foi compreendido como sintoma do retorno do impulso mimético recalcado, em uma investigação sobre o estatuto da subjetividade desde a sua formação arcaica. Este artigo analisa as premissas destas interpretações da pulsão de morte e os conflitos em sua recepção pela teoria crítica, que lançaram as bases para uma discussão ainda em andamento sobre a sua apropriação pela teoria social.
\end{abstract}

Palavras-chave: Teoria Crítica; Psicanálise; Pulsão de Morte; Emancipação; Repressão; Mimese

Abstract: In the 1930s and 1940s, Max Horkheimer investigated the origins of the
aggressivity manifested in social life, especially in the form of antisemitism. His references
to the death drive in these contexts diverge, and these differences are closely related to
broader changes in his philosophy. Initially, the concept of death drive is disregarded for
reproducing an ideological conception that justifies and hypostasizes the bond between
civilization and drive repression, a bond supposedly necessary due to the threat that its
destructive manifestations represent for life in society. Later, it was read as a symptom of
the return of the repressed mimetic impulse, within an investigation of the subjectivity
since its archaic formation. This article analyses the premises of these interpretations of
the death drive and its contentious reception in early critical theory, which laid the
foundations of a still ongoing discussion about its appropriation by social theory. Keywords: Critical Theory; Psychoanalysis; Death Drive; Emancipation; Repression; Mimesis

\footnotetext{
${ }^{1}$ Este artigo resulta da pesquisa de doutorado "Pulsão de morte e emancipação: sobre a recepção de um conceito psicanalítico na Teoria Crítica”, realizada com apoio FAPESP (processo 20/01051-1). Agradeço aos pareceristas anônimos pela avaliação e pelas sugestões para a melhoria do artigo.
}

*Doutoranda em filosofia pela Universidade de São Paulo, São Paulo, SP. Bolsista FAPESP (processo 20/01051-1). E-mail: simonebfernandes.usp@gmail.com ORCID: http://orcid.org/0000-0002-2121-3684 
A teoria das pulsões freudiana teve papel central nas discussões de Max Horkheimer, Theodor Adorno e Herbert Marcuse, autores que se uniram em torno do projeto da teoria crítica das décadas de 1930 a 1970. Ao lado de outros conteúdos da teoria psicanalítica, ela foi integrada a investigações sobre como a manipulação de disposições pulsionais vinculava os indivíduos à autoridade e ao antissemitismo no contexto fascista e sobre a adesão ao capitalismo em seus diferentes estágios. Entre os conceitos envolvidos nesta aproximação com a psicanálise, este artigo destaca a recepção conflituosa da noção de pulsão de morte [Todestrieb] nos trabalhos de Horkheimer dos anos 1930 e $1940^{2}$. Pretende-se compreender através desta investigação as motivações para a sua recusa ou para o emprego de uma versão reformulada desta noção, razões estas que residem em sua interpretação por Horkheimer e em alguns princípios básicos da teoria crítica. Este debate tem relevância histórica pois remete às bases de uma discussão sobre a sua apropriação pela teoria social para abordar a negatividade, tema ainda debatido por estudiosos contemporâneos que se vinculam ou dialogam com esta tradição.

Observa-se, na década de 1930, o conflito da concepção de pulsão de morte com as bases do materialismo interdisciplinar e do projeto teórico crítico e com as motivações para a apropriação da psicanálise no Instituto de pesquisa social, formulada com a colaboração de Erich Fromm. No período, as origens da agressividade, manifesta sobretudo como dominação, sadismo e crueldade contra as minorias, são explicadas com o recurso à primeira teoria das pulsões ${ }^{3}$. Uma década depois, em um projeto teórico crítico reelaborado em torno da crítica à razão, a pulsão de morte se torna sinônimo de mimetismo, conceito que explicita os riscos da instrumentalização do impulso mimético recalcado, na Dialética do esclarecimento (1944), obra escrita em parceria com Adorno, e em Eclipse da razão (1947). Como veremos, este conceito é considerado, em um primeiro momento, um legado ideológico do pensamento burguês, por justificar a repressão e a dominação social, e, posteriormente, é percebido como sintoma, por dizer respeito aos meios de escape do impulso mimético recalcado.

\footnotetext{
${ }^{2}$ Segue-se aqui a tradução de Trieb por pulsão. Não há espaço para reproduzirmos o debate em torno desta opção, mas importa mencionar a posição de Laplanche e Pontalis no Vocabulário da psicanálise e as recentes traduções de Pedro Heliodoro Tavares das obras de Freud pela Editora Autêntica. Como exemplo da defesa da tradução de Trieb por instinto, veja-se o trabalho de Paulo César de Souza (SOUZA, As palavras de Freud). Apesar da discordância sobre a tradução de Trieb e Verdrängung (que vertemos como recalque), a sua rigorosa tradução das obras completas de Freud será citada apenas com estes ajustes.

${ }^{3} \mathrm{O}$ termo agressividade será recorrentemente empregado aqui pois tem sentido amplo e abarca os demais afetos acima mencionados. Ele é definido por Laplanche e Pontalis como: "tendência ou conjunto de tendências que se atualizam em comportamentos reais ou fantasísticos que visam prejudicar o outro, destruílo, constrangê-lo, humilhá-lo, etc." (LAPLANCHE e PONTALIS, Vocabulário da psicanálise, 10-13); mas importa recordar que ele originalmente não se restringe a ações violentas dirigidas ao exterior, como também apontaram Laplanche e Pontalis.
} 
O conflito aqui analisado diz respeito a uma significativa modificação introduzida por Freud na psicanálise, sobre a qual uma breve introdução se faz necessária. Freud definiu pulsão, em 1915, como um conceito fronteiriço entre o psíquico e somático, estímulo interno que atua sobre o psíquico de modo constante em busca de satisfação ${ }^{4}$. Em linhas gerais, a primeira teoria das pulsões afirma o dualismo e a complementação ou oposição entre as pulsões de autoconservação (ou pulsões do Eu), voltadas à manutenção da vida e, portanto, inadiáveis e satisfeitas apenas na realidade, e as pulsões sexuais. De acordo com o princípio do prazer, o curso do processo psíquico é "incitado por uma tensão desprazerosa e toma uma direção tal que o seu resultado final deve coincidir com um abaixamento dessa tensão, ou seja, com uma evitação do desprazer ou geração do prazer”. Como seu complemento e por vezes opositor, atua o princípio de realidade, que, "sem abandonar a intenção de obter afinal o prazer, exige e consegue o adiamento da satisfação, a renúncia a várias possibilidades desta e a temporária aceitação do desprazer”. Assim, quando submetidas ao recalque, as pulsões sexuais buscam outras vias de descarga, pois são plásticas e passíveis de compensações e deslocamentos, por exemplo, por meio de sublimações, mudanças de objeto ou de meta ${ }^{6}$.

Mas, em Além do princípio do prazer (1920), Freud apresenta o dualismo entre pulsões de morte e de vida (Eros) e postula que a pulsão de morte tem precedência e é capaz de sobrepujar o princípio do prazer. A motivação para tal mudança é a percepção de que o princípio do prazer e a busca pela autoconservação não seriam suficientes para explicar todos os fenômenos psíquicos observados na clínica, sobretudo a compulsão à repetição de experiências traumáticas. A base biológica que vem a ser atribuída à pulsão de morte é a tendência encontrada nos organismos ao retorno a um estado de menor tensão, a um estado inorgânico. Neste contexto, o aspecto energético de cada uma das pulsões é crucial: ao passo que a pulsão de vida visa à união, à criação de conexões, a pulsão de morte visa à descarga total e ao desligamento. Este conceito foi questionado por muitos estudiosos da psicanálise e fora dela e o seu caráter especulativo foi reconhecido pelo próprio Freud ${ }^{7}$. Não pretendemos discorrer amplamente sobre as consequências desta mudança na teoria freudiana, apenas sobre a interpretação do seu sentido e dos seus efeitos pelos teóricos críticos aqui mencionados.

A seguir, partiremos das motivações para a aproximação da teoria crítica com a psicanálise e das teorizações de Horkheimer sobre a agressividade, sobretudo em suas

\footnotetext{
${ }^{4}$ FREUD, As pulsões e seus destinos, 19-25. É neste texto metapsicológico que Freud apresenta o conceito de pulsão em sua completude. Para menções precedentes ao termo, respectivamente no contexto do estudo da sexualidade infantil (1905) e em relação aos princípios de prazer e realidade (1911), cf. FREUD, Três ensaios sobre a teoria da sexualidade, 64 e Formulações sobre os dois princípios do funcionamento psíquico, 108ss.

${ }^{5}$ FREUD, Além do princípio do prazer $162 ; 165$.

${ }^{6}$ FREUD, As pulsões e seus destinos, 25-45.

${ }^{7}$ FREUD, Além do princípio do prazer, 232.
} 
manifestações sádicas, nos anos 1930, analisando cada elemento da interpretação da pulsão de morte que embasa a sua rejeição. A esta primeira interpretação, serão contrapostas as menções do autor à pulsão de morte como sinônimo de mimetismo nos anos 1940.

\section{A psicanálise aliada ao materialismo: recalque e caráter sadomasoquista como fontes da agressividade}

No Instituto de pesquisa social na década de 1930, passa-se a empregar contribuições da psicanálise, ao lado de outras disciplinas, para a atualização da herança marxiana, orientada por uma tentativa de identificar, teoricamente e por meio de investigações empíricas, os potenciais e bloqueios para o estabelecimento de uma sociedade emancipada. Pois embora a teoria crítica, tal como formulada por Horkheimer em 1937, esteja em continuidade com a herança marxiana, ela se posiciona de modo não dogmático em relação a esta ${ }^{8}$. Ambas almejam a emancipação social, tendo como ponto de partida a "crítica dialética da economia política", e visam à emergência de formas livres de associação humana. Tal transformação da sociedade é orientada pelo anseio pela autonomia dos indivíduos, cerceada em uma sociedade de classes organizada de modo irracional, contra os seus interesses e repressiva. Partindo deste núcleo comum, a teoria crítica procura continuamente atualizar os seus diagnósticos das possibilidades emancipatórias e dos seus obstáculos, conforme as mudanças históricas.

Colaborando com Horkheimer na realização das pesquisas empíricas do Instituto, Fromm ressaltou os aspectos materialistas dos conceitos psicanalíticos que considerava terem grande potencial para contribuir com o materialismo histórico. A integração destas duas tradições visava compreender os motivos do desaparecimento do "sujeito revolucionário”, papel que originalmente na teoria marxiana seria desempenhado pelo proletariado. Questionava-se por que os indivíduos não agiam de acordo com os seus interesses materiais, tendiam a se submeter à autoridade (da pátria, de um líder ou partido), com a qual estabeleciam um vínculo emocional, e exteriorizavam uma atitude agressiva, através do antissemitismo e, posteriormente, no suporte ao militarismo e à belicosidade da Alemanha nazista. Pelo seu forte componente emocional, estes fenômenos não podiam ser explicados simplesmente em termos de ideologia, mas precisariam ser entendidos com base em uma "psicologia do inconsciente" capaz de jogar luz sobre a estrutura pulsional (ou libidinal) compartilhada pelos membros de uma sociedade ou classe social. No projeto do "materialismo interdisciplinar", a psicanálise teve papel de destaque na explicação de "bloqueios emancipatórios" subjetivamente arraigados, tendo-se sempre em vista as condições históricas que atuam sobre a subjetividade e os propósitos da teoria

\footnotetext{
${ }^{8}$ Segue-se a sua formulação em: HORKHEIMER, Teoria tradicional e teoria crítica, 138ss.
} 
crítica ${ }^{9}$. Nessa direção, Fromm detectou que a estrutura pulsional de uma sociedade é o fator de mediação entre a sua base socioeconômica e a ideologia, por ser interiorizada pelos indivíduos já na infância através da família. Uma vez interiorizada e reproduzida pelos sujeitos, a estrutura libidinal típica de uma sociedade passa a ter certa inércia, normalmente atrasando mudanças na ordem social. Estas noções, que estavam na base do projeto empírico dos Estudos sobre autoridade e família, de 1936, foram endossadas e levadas adiante por Horkheimer em estudos sobre a cultura e a história burguesa.

O espírito burguês-capitalista, que representa o ideal a ser replicado pelos sujeitos e absorvido pela sua estrutura libidinal, é caracterizado por traços como disciplina no trabalho, acumulação, cumprimento dos deveres e ordem, em detrimento do prazer, especialmente sexual, do amor e da compaixão ${ }^{10}$. A formação destes traços é explicada em dois níveis complementares. Em primeiro lugar, na investigação da família como meio de formação do caráter, liderada por Fromm. A partir de 1932, ele propôs um deslocamento na noção de caráter, que fora empregada por Freud em referência ao desenvolvimento da sexualidade infantil e à biografia individual, para expor a gênese dos traços considerados "normais" em uma sociedade: a "adaptação da estrutura pulsional a certas condições sociais" através de formações reativas e sublimações. Nessa direção, Horkheimer e Fromm explicitaram o vínculo da família com a autoridade nos Estudos sobre autoridade e família. Ao mesmo tempo, Horkheimer analisa as bases e os efeitos dos aspectos ascéticos na história da sociedade burguesa em "Egoismus und Freiheitsbewegung [Egoísmo e movimento de libertação]”, também de 1936.

A percepção do alto grau de repressividade da sociedade burguesa capitalista permeia ambas investigações. Para compreender os seus efeitos, é aludida a diferenciação entre condenação [Verurteilung] e recalque [Verdrängung], estabelecida por Freud em $1915^{11}$. O argumento dos teóricos críticos é que, uma vez que a renúncia pulsional não é racionalmente justificável para as classes mais baixas, mas fruto da dominação social, o recalque é o único destino possível para as pulsões. Como esclarece Fromm, a consequência deste modo de defesa, que não é realizado pelo Eu por meio da condenação, mas pelo supereu, é que o papel da autoridade prevalece sobre o pensamento racional ${ }^{12}$.

A agressividade, neste contexto, não é vista como um impulso primário, mas como uma forma de compensação. A mediação para explicar esta forma de satisfação é a vinculação do caráter autoritário a uma propensão sadomasoquista, oriunda das pulsões

\footnotetext{
${ }^{9}$ Cf. HORKHEIMER, A presente situação da filosofia social e as tarefas de um instituto de pesquisas sociais, 128 e HORKHEIMER, História e psicologia, 21.

${ }^{10}$ FROMM, Die psychoanalytische Charakterologie und ihre Bedeutung für die Sozialpsychologie, 274. Tal concepção do espírito burguês-capitalista tem afinidade com a descrição weberiana em $A$ ética protestante e o espírito do capitalismo e outras discussões do período.

${ }^{11}$ Sobre a diferença entre recalque [Verdrängung] e condenação [Verurteilung], cf. FREUD, Repressão, 62.

${ }^{12}$ FROMM, Sozialpsychologischer Teil, 99-101.
} 
parciais relativas à fase anal do desenvolvimento infantil ${ }^{13}$. Fromm observa que, em vista da possibilidade de compensação para as pulsões sexuais recalcadas, são oferecidas às massas satisfações que são vantajosas às classes dominantes, sendo destacada a importância do sadismo direcionado contra os inimigos da burguesia ${ }^{14}$.

Nesta direção, no ensaio “Egoísmo e movimento de libertação”, Horkheimer apresenta uma análise histórica desde os primórdios da sociedade burguesa, orientada à compreensão do antissemitismo e da relação com o líder nazista na atualidade. São examinados os traços negativos da tradição liberal, inseridos em uma "dialética da sociedade burguesa" ${ }^{15}$. O seu objeto de estudo são períodos de exceção, os levantes de massa que favoreceram a classe burguesa desde o século XIV. Os líderes das assembleias de massas destes levantes teriam sido catalizadores de ideologias que valorizavam a renúncia pulsional, dando um exemplo de renúncia e, ao mesmo tempo, permitindo o vislumbre de um poder mais elevado, do qual os seus seguidores almejavam participar e com o qual estabeleceram um vínculo emocional. Nesta relação, está em questão o próprio sentido das renúncias que caracterizavam a vida dos sujeitos; por isso, eles encontravam consolo no pensamento de que “os outros”, aqueles que não renunciaram, estavam condenados a um terrível castigo. Exemplo da manipulação do ressentimento na direção dos inimigos da ascensão da classe burguesa é o período do Terror da Revolução Francesa:

O conceito de estrangeiro se torna sinônimo de proibido, perigoso e condenável, e a hostilidade é tanto mais fatal uma vez que seus portadores sintam que tudo isso que é proibido está irremediavelmente perdido para eles, devido à própria rigidez do seu caráter. O ressentimento pequenoburguês contra a nobreza e o antissemitismo têm funções psíquicas similares. Por trás do ódio (...) se esconde um profundo ressentimento erótico que demanda a morte de seus representantes ${ }^{16}$.

Deste modo, o niilismo vinculado à hostilidade ao prazer desemboca "em um desprezo secreto pela própria existência concreta e no ódio à felicidade dos outros" e "na

\footnotetext{
${ }^{13}$ A percepção da presença do sadismo (como elemento ativo) e do masoquismo (como a sua contraparte passiva) em um mesmo indivíduo por Freud, que Fromm toma como ponto de partida, remonta à elaboração da noção de pulsões parciais, ou seja, de pulsões sexuais que estão orientadas a um órgão ou meta específico e que tendem a se unir em pares opostos, como é o caso do sadismo e do masoquismo. Por sua vez, a investigação do caráter anal remonta a Caráter e erotismo anal, de 1908. Cf. FREUD, Três ensaios sobre a teoria da sexualidade, 64-65.

${ }^{14}$ Cf. FROMM, Über Methode und Aufgabe einer analytischen Sozialpsychologie, 30.

${ }^{15}$ Como demonstra John Abromeit com este conceito, ao passo que o momento de ascensão da burguesia conduziu a avanços no sentido da libertação da autoridade, Horkheimer identificou, após a sua consolidação como classe dominante, o abandono dos ideais iluministas que ela proclamava. Cf. ABROMEIT, Max Horkheimer and the Foundations of the Frankfurt School, 4; 417.

${ }^{16}$ HORKHEIMER, Egoismus und Freiheitsbewegung, 221.
} 
destruição prática de tudo que é alegre e feliz, como barbárie e destruição" ${ }^{17}$. É importante ressaltar o argumento de que o antissemitismo está relacionado ao ressentimento sobre pulsões sexuais recalcadas, e não movido por um desejo de destruição primário.

Com a análise do ressentimento, o autor identifica uma resposta cultural à repressividade e acena para a incipiente percepção de uma perda de capacidade de fruição, que se tornaria significativa em seus escritos da década de 1940 como parte da mutilação subjetiva. Mais do que isso, Horkheimer preza o reconhecimento, que encontra na filosofia de Nietzsche, da crueldade e do egoísmo como traços normais dos sujeitos. Embora este filósofo, assim como Freud, não tenha compreendido a sua gênese histórica, a sua posição preveniria a racionalização da crueldade e a condenação ideológica do egoísmo, que foram apropriados em prol da manutenção da dominação social. Trazer os impulsos destrutivos à consciência seria fundamental, pois considera-se (em acordo com Freud) que eles tendem a atuar por meio de racionalizações: contra a suposta maldade do oponente, na defesa da honra, etc ${ }^{18}$. Por isso, Horkheimer escreve, acerca de Nietzsche, Mandeville, Helvétius e do Marquês de Sade, apologetas do egoísmo irrestrito: "na medida em que investigaram essas moções pulsionais [Triebregungen] desprezadas e as elevaram à consciência, sem rejeitálas ou minimalizá-las, estas forças perderam seu poder demoníaco” ${ }^{19}$.

Freud indicara corretamente, portanto, a relevância da racionalização dos impulsos agressivos, mas, ao postular um ancoramento "inato" para eles na pulsão morte, teria se enredado em uma concepção pessimista da natureza humana. Pois embora acerte ao apontar a importância e até a necessidade da repressão no processo histórico até então, teria escapado a ele como a repressão e o ressentimento se tornaram traços culturais na sociedade burguesa e o seu papel na dominação social. Contra esta tendência, a meta de Horkheimer segue materialista: a destruição da visão moralista sobre o prazer dependeria da eliminação da dominação de classe que está em sua origem. Em vista da menor repressividade, a disrupção dos impulsos destrutivos não prevaleceria em uma sociedade orientada pelos interesses comuns dos indivíduos. Neste contexto, a rejeição da pulsão de morte para dar conta da agressividade socialmente manifesta advém de uma determinada

\footnotetext{
${ }^{17}$ HORKHEIMER, Egoismus und Freiheitsbewegung, 220.

18 HORKHEIMER, Egoismus und Freiheitsbewegung, 228-229. Horkheimer menciona a interpretação nietzscheana da crueldade como "remédio do orgulho ferido", ou seja, também como compensação. Ao mesmo tempo, a possibilidade de se educar tais impulsos racionalmente pelos canais "do trabalho e do conhecimento" é expressa, indicando a percepção do potencial da sublimação. Cf. HORKHEIMER, Allgemeiner Teil, 59 [trad. bras. "Autoridade e família”, 222].

${ }^{19}$ HORKHEIMER, Egoismus und Freiheitsbewegung, 230. Sobre a contraposição de Freud e Nietzsche em relação ao tema da crueldade, cf. GAYRAUD, Nietzsche: les Lumières et la cruauté. De l'interprétation de Nietzsche par la Théorie critique; GENEL, Autorité et Émancipation, 148-164. Sobre a recepção de Nietzsche por Horkheimer, cf. FERNANDES, A dimensão subjetiva da dominação social: a recepção de Nietzsche na teoria crítica de Horkheimer nas décadas de 1930 e 1940, capítulo 1.
} 
interpretação deste conceito e do seu conflito com as bases da teoria crítica e do materialismo interdisciplinar, a seguir analisados.

\section{Bases da interpretação da pulsão de morte na teoria crítica dos anos 1930}

A pretensão de explicar fenômenos sociais com o recurso à pulsão de morte advém não apenas do interesse de Freud no social, expresso mesmo antes da segunda teoria das pulsões, mas devido a questões metodológicas, a saber, porque concluiu que a pulsão de morte tendia a agir em silêncio quando não se expressava no exterior e que a pulsão de agressão seria o seu "derivado e representante maior" ${ }^{20}$. É essa descrição da pulsão de morte o alvo de Horkheimer e Fromm nos escritos aqui analisados. Importa observar que os autores deixam em segundo plano outros aspectos abarcados pela teorização freudiana que, recorde-se, estava voltada à compreensão de fenômenos da clínica que não podiam ser explicados pelas pulsões de autoconservação e sexuais. Entre estes aspectos, estão a compulsão de repetição, a atuação conjunta da pulsão de morte com Eros, o seu papel na formação do supereu, outros possíveis destinos desta pulsão e o aspecto energético de redução de tensões relacionado ao princípio do Nirvana.

As afirmações de Freud sobre o valor da pulsão de morte na compreensão da vida social são recusadas por Horkheimer e Fromm por três razões. Em primeiro lugar, a concepção de uma pulsão voltada ao retorno ao estado inorgânico entra em contradição com o princípio materialista básico de luta pela vida. Nesse sentido, Fromm, principal colaborador de Horkheimer no período, declarara que "a atividade psíquica humana se desenvolve como adaptação aos processos e necessidades da vida, e que as pulsões, como tal, são justamente opostas ao princípio biológico da morte" ${ }^{21}$. No modelo integrado por pulsões de autoconservação e sexuais, as pulsões tenderiam a se aliar na conservação do indivíduo e da espécie e, mesmo quando a pulsão sexual se opõe à autoconservação, esta oposição é contingente, não está inscrita em sua natureza. Note-se também que o foco sobre a adaptação às situações socioeconômicas, iniciada na família e renovada através de prêmios sociais, é central na teorização sobre o caráter autoritário. Neste quadro explicativo, o masoquismo advém do fato de que "a vida é determinada por poderes que estão fora do indivíduo" e da adaptação à necessidade de submissão. O sadismo tampouco é primário, mas uma compensação pela impotência ${ }^{22}$.

No entanto, ao introduzir o segundo dualismo pulsional, Freud identificara "um impulso, presente em todo organismo vivo, tendente à restauração de um estado anterior, que esse ser vivo teve de abandonar por influência de perturbadoras forças externas”. Trata-se também de um ímpeto de conservação, mas à conservação de um estado anterior à

\footnotetext{
${ }^{20}$ FREUD, O mal-estar na civilização, 90.

${ }^{21}$ FROMM, Über Methode und Aufgabe einer analytischen Sozialpsychologie, 28, nota 2, grifo nosso.

${ }^{22}$ FROMM, Sozialpsychologischer Teil, 120.
} 
vida: "o inanimado [que] existia antes que o vivente". Os impulsos voltados à autoconservação, neste quadro, já não são entendidos como primordiais, mas como pulsões parciais $^{23}$ e é pressuposta a existência de um masoquismo primário ${ }^{24}$, cuja energia tende a ser exteriorizada como agressividade. Nas palavras de Freud, neste novo contexto supõe-se que o sadismo é "uma pulsão de morte que foi empurrada do Eu pela influência da libido narcísica”, ou seja, trata-se de uma pulsão de morte deslocada ${ }^{25}$. Posicionando-se em relação a estes dois modelos, Horkheimer ressalta o caráter dialético das pulsões na primeira teorização freudiana, pois "relacionavam a construção do destino individual inteiramente à sociedade e à interação entre fatores externos e internos”, de modo que as proibições sociais seriam condições fomentadoras do sadismo ${ }^{26}$.

Em segundo lugar, Horkheimer percebe na pulsão de morte um movimento de Freud na direção do puramente biológico, em detrimento do suposto aspecto histórico de alguns de seus conceitos anteriores a $1920 .{ }^{27}$ Esta interpretação da pulsão de morte como uma tendência inata, biologicamente determinada, como a "primeira pulsão" voltada ao retorno ao inanimado, entra em conflito com o ímpeto da teoria crítica em empregar a psicanálise como ciência auxiliar da história (como propusera Horkheimer em 1932) e, assim, compreender os traços de caráter dos indivíduos em interação com a sociedade em que vivem e com a sua situação de classe. Horkheimer e Fromm enfatizam que o principal fator condicionante na estrutura psíquica dos sujeitos não é uma propensão biológica, mas o montante de repressão demandado pela sociedade, exercido em graus distintos sobre diferentes classes sociais e tendo efeitos sobre suas metas pulsionais e sobre a formação e atuação das instâncias psíquicas do Eu e do supereu.

Tais interpretações da pulsão de morte a colocam em pleno conflito com as propostas do materialismo interdisciplinar e com o ímpeto histórico da teoria crítica de realizar diagnósticos conforme as mudanças na sociedade. Mas, mais importante e por trás

${ }^{23}$ FREUD, Além do princípio do prazer, 202;204-205, grifos do autor. Nesta obra, Freud apresenta também o princípio do Nirvana, como esforço constante de abolição de tensões. Esta discussão é complementada em “O problema econômico do masoquismo" (1924), mas como os autores aqui analisados não se detêm sobre o aspecto econômico das pulsões, não abordaremos esta obra.

${ }^{24}$ Como escrevem Laplanche e Pontalis: “este masoquismo chama-se 'primário' porque não sucede a um tempo em que a agressividade estaria voltada para um objeto exterior, e também porque se opõe a um masoquismo secundário, que se define como um retorno do sadismo sobre a própria pessoa e se acrescenta ao masoquismo primário” (LAPLANCHE e PONTALIS, Vocabulário da psicanálise, 274).

${ }^{25}$ FREUD, Além do princípio do prazer, 225-226.

${ }^{26}$ HORKHEIMER, Egoismus und Freiheitsbewegung, 224-225. Note-se também que, segundo Horkheimer, a pulsão de morte é o ponto culminante da evolução do papel do ódio e do sadismo na teoria freudiana, que já fora ampliado com a teoria do narcisismo, de 1914. Sintetizando este movimento em As pulsões e seus destinos (1915), Freud afirmara que o ódio é um sentimento mais antigo do que o amor e que ele "brota do repúdio primordial do Eu narcísico perante o mundo externo portador de estímulos”, ou seja, está relacionado às pulsões de autoconservação ou do Eu (FREUD, As pulsões e seus destinos, 61).

${ }^{27}$ Cf. HORKHEIMER, Egoismus und Freiheitsbewegung, 225. 
desta questão teórica e metodológica está o conflito da pulsão de morte com o seu fundamento, a noção de emancipação. Afinal, a concepção de uma agressividade inata nos sujeitos, a postulação de um masoquismo primário que pode se converter em sadismo e a exacerbação do biológico em detrimento do histórico colocam em questão a própria possibilidade de se atingir uma sociedade emancipada, caracterizada pela autonomia individual e pela menor repressividade, o que se traduziria na erradicação da dominação social e no estabelecimento de formas de organização racionais e livres.

A visão freudiana da política e das possibilidades de associação humana é problematizada em "Egoísmo e movimento de libertação". Identifica-se em filósofos da época burguesa mais diversos, como Maquiavel, More, Hobbes e Rousseau, um traço comum: a condenação do egoísmo, ou seja, das reivindicações de prazer e felicidade, como atitudes nocivas e perigosas que poderiam trazer prejuízos à sociedade, independente de se estes filósofos caracterizaram a natureza humana como boa (e apenas posteriormente corrompida) ou má. Horkheimer percebe haver uma "contaminação moral” em ideias antropológicas sobre o homem, que advém de uma contradição desta sociedade: a necessidade da moral idealista como justificação da dominação social e da repressividade impostas sobre grandes camadas da população. Freud, com a sua concepção de pulsão de morte, teria se aliado a este pessimismo burguês ${ }^{28}$. Por isso, Horkheimer observa, sobre o juízo de Freud de que a pulsão de morte ia contra ideias religiosas e convenções sociais, que ele não as contrariava, como pretendia, mas que as reproduzia e levava adiante o legado ideológico do pensamento burguês.

É problemático que, segundo Freud, qualquer melhoria duradoura das condições sociais seria impossível em vista da ameaçada constantemente de desintegração da civilização por uma hostilidade mútua primária, postulada por meio da pulsão de morte, cuja transformação sob Eros é um traço adquirido e secundário ${ }^{29}$. De fato, Freud indica a fragilidade das forças psíquicas que atuam em sentido contrário a esta agressividade, defendendo que a subordinação das massas pode ser justificável em vista da "miséria psicológica” que tende a irromper quando "a ligação social é estabelecida principalmente pela identificação dos membros entre si, e as individualidades que podem liderar não adquirem a importância que lhes deveria caber na formação das massas”30. Em outras

\footnotetext{
${ }^{28}$ Veja-se a parte I de HORKHEIMER, Egoismus und Freiheitsbewegung, 161-172; 226; 254.

${ }^{29}$ Cf. O mal-estar na civilização, 77-78. Horkheimer cita um trecho de "Por que a guerra”, texto que apresenta uma interlocução de Freud com Einstein: "os motivos ideais só teriam servido como pretexto para os apetites destrutivos; outras vezes, no caso das atrocidades da Santa Inquisição, por exemplo, achamos que os motivos ideais se impuseram à consciência, enquanto os destrutivos lhes trouxeram um reforço inconsciente"; por fim, o veredito é de que "não há perspectiva de poder abolir as tendências agressivas no ser humano" (FREUD, “Por que a guerra?”, 428-429, citado em HORKHEIMER, Egoismus und Freiheitsbewegung, 225).

30 FREUD, $O$ mal-estar na civilização, 73. Freud também menciona o antissemitismo como um desdobramento desta agressividade (páginas 80-82).
} 
passagens de sua obra, é evidente o ceticismo em relação à pretensão do marxismo de, "no curso de poucas gerações, mudar a natureza humana de tal forma que os homens convivam quase sem atritos na nova ordem social e que se dediquem ao trabalho sem nenhuma coerção”. Freud também se opõe à ideia de que a abolição da propriedade privada iria eliminar este traço da natureza humana ${ }^{31}$. Com base nestas afirmações, Horkheimer julga que aceitar a pulsão de morte como ameaça inata e constante sobre a civilização significaria aquiescer a um hipostasiamento da necessidade de repressão, da dominação social e do governo de uma classe que liderasse as massas e contivesse tais impulsos.

Em suma, na discussão sobre a repressão, estão implicados tanto os supramencionados bloqueios emancipatórios oriundos dos subprodutos do recalque, como também um desafio para a concepção de emancipação da teoria crítica. Quanto ao primeiro ponto, recorde-se que o caráter sadomasoquista é concebido como fruto de uma sociedade repressiva e o sadismo seria uma satisfação substitutiva manipulável. Uma vez que está em jogo o recalque de pulsões sexuais, Horkheimer indica ser uma falha deixar de lado a pressão da cultura sobre tais pulsões e os efeitos do seu recalcamento em $O$ malestar na civilização, enfatizando a sua pressão sobre a "pulsão destrutiva inata"32. Mas especialmente significativo é o conflito da noção de pulsão de morte com a meta de redução da repressão, tomada como requisito da autonomia individual. Evidência disso é a referência de Horkheimer ao egoísmo de modo não moralizante, motivado não só por um diagnóstico histórico, mas pela vinculação da sua concepção de materialismo à busca pela felicidade individual, como uma meta fundamental que não carece de justificação elemento basilar da teoria crítica nos anos 1930, como argumenta John Abromeit:

A crítica de Horkheimer às tentativas ideológicas de se prover aos indivíduos compensação simbólica para o sofrimento ou sacrifício reais é parte de sua tentativa de resgatar os aspectos progressivos do legado burguês - sua defesa dos interesses materiais de indivíduos reais e do seu direito a buscar a felicidade - e permaneceria uma pedra angular de sua teoria crítica nos anos 1930 e posteriormente ${ }^{33}$.

\footnotetext{
${ }^{31}$ FREUD, Novas conferências introdutórias à psicanálise, 351-353 e FREUD, O mal-estar na civilização, 79. ${ }^{32}$ HORKHEIMER, Egoismus und Freiheitsbewegung, 226.

${ }^{33}$ ABROMEIT, Max Horkheimer and the Foundations of the Frankfurt School, 173. Veja-se as afirmações de Horkheimer (em ensaios de 1933-1934), de que "toda fundamentação racional de uma ação pode relacionar-se somente com a felicidade dos homens" (HORKHEIMER, Da discussão do racionalismo na filosofia contemporânea, 124) e que a busca da felicidade é "um fato natural, que não precisa de qualquer justificativa" (HORKHEIMER, Materialismo e metafísica, 57). A sua crítica à metafísica e ao irracionalismo filosófico neste período é orientada por duas razões: a percepção dos seus efeitos contrários à noção de emancipação, mas também a sua contradição com o princípio básico de busca pela felicidade implícito em sua concepção do materialismo.
} 
A pulsão de morte, recorde-se, também torna questionável o alcance da ideia de busca pela felicidade pelos indivíduos, por estar “além do princípio do prazer" e postular um masoquismo primário que pode ser exteriorizado e depois retornar contra o sujeito.

O pensamento do Horkheimer passa por mudanças significativas a partir de $1938^{34}$, em vista do seu diagnóstico sobre bloqueios e potenciais emancipatórios, que conduz à reinterpretação também do conceito de pulsão de morte. Neste novo contexto, o autor passa a colaborar com Adorno e se afasta de Fromm ${ }^{35}$.

\section{Pulsão de morte e mimese}

Para compreendermos o desenvolvimento da teorização da agressividade por Horkheimer nos anos 1940, importa notar como ele rompeu com o modo de explicação do antissemitismo baseado no caráter sadomasoquista, nos capítulos "Elementos de antissemitismo" da Dialética do esclarecimento, obra escrita em parceria com Adorno, e "Revolta da natureza" de Eclipse da razão. Tal mudança advém de um diagnóstico de ampliação da dominação social em vista da ausência de crítica e de uma tendência quase totalizante de adaptação ao poder, expressos nas vitórias do fascismo na Europa, na opressão na URSS e pela indústria cultural. Não será possível detalhar esta mudança, mas é crucial assinalar a maior negatividade ali presente, em vista da postulação do entrelaçamento entre a razão e a dominação da natureza interna e externa desde os primórdios da humanidade e do questionamento radical do progresso ${ }^{36}$. Por isso, a antropologia da época burguesa é substituída por uma nova investigação antropológica sobre a formação subjetiva em sua origem mais remota, da qual a psicanálise é uma das ferramentas. Ela já não tem o papel de mediação entre base e superestrutura, pois considera-se que a economia perdera espaço para a dominação política; tampouco está

\footnotetext{
${ }^{34}$ Sobre esta transição, cf. ABROMEIT, Max Horkheimer and the Foundations of the Frankfurt School, 336ss.

${ }^{35} \mathrm{Na}$ segunda metade da década de 1930, Fromm foi se distanciando gradativamente da linha de pesquisa desenhada no Instituto, na direção do assim chamado revisionismo da teoria freudiana. Por revisionismo, nomeia-se uma corrente de psicanalistas (que incluiu Karen Horney e Harry Sullivan) que questionaram pontos chave de sua teoria, como a teoria das pulsões e o papel da sexualidade. Fromm foi fortemente criticado por Horkheimer, Adorno e Marcuse, que o acusaram de minimizar a agressividade ao abandonar o potencial crítico da teoria das pulsões e de "sociologizar" a psicanálise. Cf. ABROMEIT, Max Horkheimer and the Foundations of the Frankfurt School, 336-348; ROUANET, Teoria critica e psicanálise, 50-68, JAY, A imaginação dialética, 133-162; RICKERT, The Fromm-Marcuse Debate Revisited, 358-361.

${ }^{36}$ Um modo elucidativo para descrever a mudança da teoria crítica nos anos 1940 é contrastar o papel concedido ao domínio sobre a natureza: ao passo que na década de 1930 era signo do avanço técnico que poderia promover a melhoria de vida dos indivíduos, agora é vinculado a um processo de dominação totalizante da natureza interna e externa e às suas decorrências regressivas. Para a análise do tema da dominação da natureza, seguimos: CHIARELLO, Das lágrimas, das coisas, 37-38.
} 
integrada em um projeto interdisciplinar, que fora abandonado por Horkheimer devido a uma desconfiança mais ampla sobre a ciência e o alcance do problema do positivismo. Mas a psicanálise fornece, ainda, conceitos e análises profícuos para a teoria crítica.

Quanto aos temas da década anterior aqui discutidos, uma mudança importante é a passagem da teorização sobre a família como fator de mediação entre indivíduo e sociedade para o foco sobre o tema da reificação, tomado em sentido historicamente amplo $^{37}$. Note-se também as consequências do fato de a renúncia pulsional ser caracterizada como dominação da natureza interna, como um processo de sacrifício. $\mathrm{Na}$ análise do mito de Ulisses, o herói renuncia, ao mesmo tempo, às ofertas libidinais das forças míticas (a atração das sereias e a primeira investida de Circe), mas também ao retorno ao inanimado, à recaída na natureza que ameaça a sua individualidade recém formada. Neste processo, distintamente da investigação das decorrências do recalque, a dominação da natureza interna conduz não a satisfações substitutivas, mas à mutilação subjetiva vinculada à perda da capacidade de prazer e de fruição, em um aprofundamento de um diagnóstico que já se insinuava no ensaio de 1936 sobre o egoísmo. Além disso, na tematização do antissemitismo já não é empregada a caracterologia, mas noções como ressentimento, projeção e paranoia, sendo os dois últimos apenas implícitos no referido ensaio de 1936. Apesar destas mudanças e aprofundamentos na análise do tema, novamente o antissemitismo é vinculado não a uma suposta agressividade inata, mas à vontade de destruição advinda da renúncia, um movimento agora explicitado com o recurso à noção de impulso mimético. É nesse contexto que a pulsão de morte é referida.

Em sua origem, a mimese é um mecanismo de autoconservação através da adaptação ao meio. Como escrevem os autores, ao sinal do perigo,

quando o humano quer se tornar como a natureza, ele se enrijece contra ela. A proteção pelo susto é uma forma do mimetismo. Essas reações de contração no homem são esquemas arcaicos da autoconservação: a vida paga o tributo de sua sobrevivência assimilando-se ao que é morto ${ }^{38}$.

Este impulso atua livremente em uma fase mais arcaica do desenvolvimento filogenético ou ontogenético e é ultrapassado e recalcado pela racionalidade, que se torna a promotora da autoconservação ${ }^{39}$. Por isso, é um impulso proscrito no mundo burguês e tornado tabu. Considera-se que o antissemitismo e todo ódio contra minorias receberiam energia da mimese recalcada, satisfeita tanto na imitação do judeu pelo antissemita nos

\footnotetext{
${ }^{37}$ Cf. a mudança de diagnóstico sobre a família, em HORKHEIMER, Authoritarianism and Family Today, e a análise dos deslocamentos quanto ao tema da autoridade, em GENEL, Autorité et Émancipation, 148-164.

${ }^{38}$ HORKHEIMER e ADORNO, Dialética do esclarecimento, 149. Abordamos aqui a discussão sobre a mimese da perspectiva de Horkheimer, em comparação à sua tematização do antissemitismo na década anterior, mas importa destacar a importância e a amplitude do tema da mimese em investigações anteriores de Walter Benjamin e no pensamento de Adorno, inclusive após a publicação da Dialética do esclarecimento. ${ }^{39}$ HORKHEIMER e ADORNO, Dialética do esclarecimento, 149; HORKHEIMER, Eclipse da razão, 130-135.
} 
discursos nazistas como na reprodução sobre ele da violência e da opressão uma vez instauradas contra a sua própria natureza. A esta rebelião da natureza instrumentalizada em rituais pelo aparato fascista, os autores dão o nome de mimese da mimese, ressaltando que não se trata da mimese genuína, mas de uma falsa projeção, que toma como ponto de partida o ato de projetar a hostilidade sobre o mundo exterior, um mecanismo típico da paranoia que é apropriado em favor da dominação social.

A pulsão de morte é relacionada a esta análise da mimese em uma nota denominada "Fragmento de uma teoria do criminoso", da Dialética do esclarecimento. Descreve-se o criminoso como portador de uma "tendência profundamente arraigada no ser vivo e cuja superação é um sinal de evolução: a tendência a perder-se em vez de impor-se ativamente no meio ambiente, a propensão a se largar, a regredir à natureza. Freud denominou-a pulsão de morte, Caillois le mimétisme”. O crime seria uma tentativa de oposição "ao progresso inflexível”, mas por meio de uma "negação desprovida de resistência" ${ }^{40}$. Note-se, em primeiro lugar, que a pulsão de morte é apresentada como um modo possível de nomear este fenômeno, tendo, assim, um caráter de sintoma e não de fator explicativo; ou seja, o conceito de pulsão de morte é interpretado, assim como o psicanalista interpreta as queixas de seus pacientes buscando as suas causas mais profundas. A pulsão de morte representaria um modo possível, mas não o único, de pensar a reprodução na atualidade daquele ímpeto que Katia Genel descreveu como "a identificação reificante ou a mimese de morte, ou seja, o mecanismo pelo qual a própria constituição do sujeito é ameaçada”, análise proposta em referência a uma situação histórica em que é escassa a resistência dos sujeitos e a identificação com a realidade tem primazia ${ }^{41}$.

Nos interessa ressaltar esse deslocamento conceitual da pulsão de morte no contexto do crime, como revolta da natureza: ela ainda é vinculada a um ímpeto contrário à individuação e secundariamente promotor da agressividade, mas não visa à recaída em um estado inorgânico; se o sujeito imita o inorgânico, é apenas para propiciar a autoconservação, sendo assim esta pulsão esvaziada do masoquismo primário. A pulsão de morte é ainda relacionada à revolta da natureza na nota "Interesse pelo corpo" da Dialética, como uma interpretação psicológica (entre outras possíveis) da manifestação de irracionalidade, dominação e crueldade na relação dos sujeitos com o seu corpo e com o corpo de outros, ou seja, aproximada do masoquismo e do sadismo ${ }^{42}$. Nesse cenário, a compulsão à crueldade e à destruição é atribuída ao afastamento do aspecto natural da humanidade, em analogia com outra ideia freudiana: de que o surgimento do nojo e o afastamento do corpo surgem com a evolução da espécie. Em suma, ao repensarem a interpretação freudiana da pulsão de morte na Dialética, Horkheimer e Adorno recusam

\footnotetext{
${ }^{40}$ HORKHEIMER e ADORNO, Dialética do esclarecimento, 187. Sobre o crime como "revolta da natureza", cf. HORKHEIMER, Eclipse da razão, 107.

${ }^{41}$ GENEL, Autorité et Émancipation, 158.

${ }^{42}$ HORKHEIMER e ADORNO, Dialética do esclarecimento, 191.
} 
novamente a hipótese do masoquismo primário e indicam a primazia da pulsão de autoconservação na qual se baseia a mimese; a partir daí, identificam o recalque do impulso mimético como fonte de manifestações regressivas que ameaçam a vida social em maior magnitude do que fora proposto na década anterior.

Estas menções à pulsão de morte tomam um caminho não ortodoxo, pois as reflexões de Freud sobre a força disruptiva do masoquismo primário exteriorizado não são tomadas literalmente, mas como sintomáticas de algo que deve ser ainda objeto de investigação. Isso é evidenciado na posição declarada do autor sobre a psicanálise e sobre a pulsão de morte. Em primeiro lugar, nos protocolos de discussão para a elaboração da Dialética, a psicanálise é ainda julgada insuficiente por não compreender as transformações históricas do indivíduo. Por outro lado, diferente do que foi sustentado em 1936, afirma-se que o desprezo pelo gênero humano tem um sentido crítico, o que implica de certo modo ceder terreno, admitir que há ali a uma apreensão correta, embora não adequadamente fundamentada ${ }^{43}$. De modo ainda mais elucidativo, em uma correspondência de 1942 destinada a Leo Löwenthal, Horkheimer declara que os conceitos ligados à pulsão de morte são categorias antropológicas, que explicitam a formação dos sujeitos em interação com a sociedade, independente do discernimento do seu alcance por Freud: "mesmo nos pontos em que não concordamos com a interpretação e o uso delas por Freud, constatamos que sua intenção objetiva é profundamente correta” ${ }^{44}$.

\section{Considerações finais}

Por fim, nos interessa indicar algumas discussões posteriores sobre a pulsão de morte, fomentadas por Marcuse, a partir da publicação de Eros e civilização (1955), e por autores e autoras que se vinculam ou debatem com a teoria crítica a partir dos anos 1990, após duas décadas em que a teoria das pulsões perdeu espaço dentro desta tradição. Observamos que a recusa inicial da pulsão de morte nos termos propostos por Freud esteve ancorada em sua interpretação como um ímpeto de agressividade inato e trans-histórico que ameaça inexoravelmente a civilização e a sua posterior reformulação deveu-se à suposta falta de mediações para a compreensão de suas origens. Há, no entanto, outros modos de fazer referência a esta pulsão. O próprio Freud, apesar de enfatizar o risco que ela representava para a civilização e o seu fundamento biológico, apontou as suas distintas manifestações e a sua ação conjunta com $\operatorname{Eros}^{45}$. Avançando nesta direção, nos anos 1950,

\footnotetext{
${ }^{43}$ HORKHEIMER, Gesammelte Schriften, v. 12, 440-441 (discussão de Horkheimer e Adorno em 06.01.1939).

${ }^{44}$ Carta de Horkheimer a Löwenthal de 31.10.1940 apud JAY, A imaginação dialética, 150, grifo nosso.

${ }^{45}$ Por exemplo, em "Por que a guerra?", Freud assevera que "quase nunca a pulsão de uma espécie pode agir isoladamente, sempre se acha ligada - amalgamada, dizemos - a um certo montante de sua contrapartida, que modifica a meta ou, ocasionalmente, permite-lhe alcançá-la”. O autor ressalta, por fim, que ambas as
} 
Marcuse tentou conciliar o emprego da pulsão de morte com a possibilidade de uma sociedade livre da surplus repressão (mais-repressão), ou seja, do montante de repressão que ultrapassa o necessário à reprodução social. $O$ autor elenca a diversidade de manifestações da pulsão de morte, a sua atuação em conjunto com Eros e a energia que fornece ao supereu. Mas o seu argumento principal é que esta pulsão, que está vinculada à tensão desprazerosa, perderia força quanto mais próximo se estivesse de um estado de “constante gratificação”, após ser minimizada a repressão social ${ }^{46}$. Esta proposta foi criticada por Joel Whitebook como signo de onipotência e de uma compreensão materialista estreita do que é necessidade [Ananke] e, mais recentemente, caracterizada por Amy Allen como uma solução equivocada ao desafio colocado pela teorização da pulsão de morte ${ }^{47}$.

Da magnitude da ameaça que a pulsão de morte supostamente representa para a civilização resultou o seu conflito com uma certa concepção de emancipação. Ela se confronta com o seu conteúdo manifesto de busca pela autonomia e minimização da repressão e com um aspecto implícito, mas extremamente significativo: a pressuposição de um determinado tipo de sujeito que subjaz a estas metas, um sujeito que busca a felicidade e a autoconservação primariamente e que só como segunda natureza adquire a destrutividade contra si e contra os outros. Recordemos que nem mesmo nos escritos da década de 1940 a tese do masoquismo primário foi aceita por Horkheimer e Adorno: a formação individual estaria orientada à autoconservação, inicialmente alcançada através da mimese; e o convite à fusão (no enfrentamento de Ulisses com as potências míticas ou em manifestações posteriores do impulso mimético proscrito) só seria atraente por propiciar uma reconciliação com a natureza, ainda que falsa. Embora possam implicar a aniquilação do Eu e o retorno à animalidade, na origem destes fenômenos está a busca pelo prazer irrestrito, a promessa de felicidade e não a redução de tensões ou o retorno a um estado inorgânico. Assim, a dimensão energética da pulsão de morte (relacionada ao princípio do Nirvana) não é apropriada por Horkheimer e Adorno.

Central entre os desafios da pulsão de morte à emancipação é o seu conflito com a noção de progresso histórico, na medida em que a sua tendência disruptiva seria ameaçadora a qualquer avanço civilizatório. Nos anos 1930, embora não seja adequado

pulsões, atuando em conjunto ou oposição, são responsáveis pelos fenômenos da vida e não devem ser percebidas em termos de "bem" ou "mal" (FREUD, Por que a guerra?, 426-427).

${ }^{46}$ MARCUSE, Eros and Civilization, 51-52; 234-235. O papel da energia da pulsão de morte na formação do supereu não foi tematizado por Horkheimer, embora ele e Fromm façam referência às três instâncias psíquicas da segunda tópica freudiana. Sobre as decorrências problemáticas do vínculo da pulsão de morte com o supereu para a teoria social, cf. RAULET, Sur le statut de l'agressivité et de la pulsion de mort dans "Malaise dans la civilisation".

${ }^{47}$ WHITEBOOK, Perversion and Utopia, 39-41. Nesta obra de 1995, Whitebook também afirma a premência atual do problema da onipotência, após os avanços na compreensão do narcisismo e do desenvolvimento préedípico na psicanálise. Cf. a retomada do debate em 2017: ALLEN, Progress \& The Death Drive. 
dizer que Horkheimer esteja comprometido com uma crença no progresso, pois a história burguesa é descrita por ele como um processo marcado por avanços e recuos, há ainda a expectativa pelo estabelecimento de uma organização social racional e pela erradicação da dominação social. Contra tal possibilidade, como vimos, a pulsão de morte pertenceria a um legado ideológico cético em relação a qualquer avanço duradouro. Na década de 1940, por sua vez, em que Horkheimer e Adorno declaram que está em andamento a regressão da sociedade em vez do progresso, a ameaça da pulsão de morte integra as suas teorizações, não como fator explicativo da barbárie vigente, mas como um dos seus sintomas. Mais do que isso, em ambos os períodos, não é sequer mencionada pelos teóricos críticos a solução aventada por Freud: a esperança de que os avanços do progresso técnico e da evolução cultural propiciassem o estabelecimento de uma "ditadura da razão" ${ }^{48}$. Isso ocorre, em um primeiro momento, pois esta proposição conflita com a percepção de Horkheimer (nos anos 1930) da dominação social como fonte da agressividade socialmente manifesta, mas também porque justamente a racionalidade e o progresso técnico vêm a ser questionados por Horkheimer e Adorno nos anos 1940.

Importa também notar que a pulsão de morte está no cerne de interpretações sobre o pensamento de Freud como um todo, lido como um autor pessimista alinhado à condenação ideológica do prazer, mas também como alguém que identificou tendências em seu tempo, mas não deu conta de suas origens. Nesta direção, no ensaio de 1936 e na correspondência de 1942 acima discutidos, Horkheimer assinala a importância da mudança em seu pensamento com a introdução da pulsão de morte, indicando que Freud compreendera adequadamente uma mudança nas subjetividades, mas não as suas causas.

A aparente contradição sobre o progresso inscrita na letra do texto freudiano, predominantemente pessimista, mas também identificando potencialidades no progresso técnico e cultural, permite outra interpretação do autor: como um representante do “esclarecimento sombrio" que tentou integrar as reivindicações do contraesclarecimento na defesa deste legado, como propõe Whitebook ${ }^{49}$. Também segundo Allen, que investiga o estatuto da noção de progresso na teoria crítica precedente e na contemporaneidade, a postulação da pulsão de morte não implica necessariamente um posicionamento em favor de uma utopia marcuseana ou de um pessimismo conservador. A autora situa Freud como um pensador do esclarecimento cético, pois portador de uma "visão irreconciliada dos conflitos entre o progresso civilizacional e a pulsão de morte" que o previne contra a crença ingênua no progresso, mas também contra os inimigos da civilização, argumento

\footnotetext{
${ }^{48}$ Sobre a "ditadura da razão", lê-se: “a natureza da razão garante que ela não deixará, então, de conceder o devido lugar aos afetos humanos e ao que é determinado por eles. Mas a coação comum exercida por esse domínio da razão se revelará o mais forte laço unificador entre os homens e abrirá caminho a outras unificações" (FREUD, Novas conferências introdutórias à psicanálise, 340). Cf. também: FREUD, Por que a guerra?, 430-435.

${ }^{49}$ WHITEBOOK, Freud: An Intellectual Biography, "My Second Theme”.
} 
reforçado com a citação de uma afirmação de Freud segundo a qual deve-se evitar identificar a civilização com uma tendência ao aperfeiçoamento ${ }^{50}$.

Os temas envolvidos na discussão sobre a pulsão de morte nos anos 1930 e 1940 aqui analisados, portanto, remetem a um debate ainda em andamento e envolvem questões sobre a possibilidade de se abarcar a totalidade da concepção da pulsão de morte tal como concebida por Freud em uma teoria social, sobre a sua negatividade e, como alternativa, a sua reformulação ou reinterpretação.

\section{Referências}

ABROMEIT, J. Max Horkheimer and the foundations of the Frankfurt School. New York: Cambridge University Press, 2011.

ADORNO, T.; HORKHEIMER, M. Dialética do esclarecimento: fragmentos filosóficos. Trad. Guido Antonio de Almeida. Rio de Janeiro: Zahar, 2006.

ALlEN, A. Progress \& The Death Drive. Radical critique, 2017. Disponível em: http://www.radicalcritique.org/2017/11/progress-death-drive-article-by-amy.html Acesso: 07.06.2020.

CHIARELlO, M. Das lágrimas das coisas: estudo sobre o conceito de natureza em Max Horkheimer. São Paulo: Editora da Unicamp, 2001.

FERNANDES, S. A dimensão subjetiva da dominação social: a recepção de Nietzsche na teoria crítica de Horkheimer nas décadas de 1930 e 1940. Dissertação (Mestrado em filosofia). Faculdade de Filosofia, Letras e Ciências Humanas, USP, São Paulo, 2019.

FREUD, S. Formulações sobre os dois princípios do funcionamento psíquico (1911). Trad. Paulo César de Souza. In: Obras completas, v. 10. São Paulo, Cia das Letras, 2010.

FREUD, S. Repressão (1915). Trad. Paulo César de Souza. In: Obras completas, v. 12. São Paulo, Cia das Letras, 2010.

FREUD, S. Além do princípio do prazer (1920). Trad. Paulo César de Souza. In: Obras completas, v. 14. São Paulo, Cia das Letras, 2010.

FREUD, S. O mal-estar na civilização (1930). Trad. Paulo César de Souza. In: Obras completas, v. 18. São Paulo, Cia das Letras, 2010.

FREUD, S. Meu contato com Josef Popper-Lynkeus (1932). Trad. Paulo César de Souza. In: Obras completas, v. 18. São Paulo, Cia das Letras, 2010.

FREUD, S. Por que a guerra? Carta a Einstein (1932). Trad. Paulo César de Souza. In: Obras completas, v. 18. São Paulo, Cia das Letras, 2010.

\footnotetext{
${ }^{50}$ ALLEN, Progress \& The Death Drive, s.p. Cf. O mal-estar na civilização, 58.
} 
FREUD, S. Novas conferências introdutórias à psicanálise (1933). Trad. Paulo César de Souza. In: Obras completas, v. 18. São Paulo, Cia das Letras, 2010.

FREUD, S. Três ensaios sobre a teoria da sexualidade (1905). Trad. Paulo César de Souza. In: Obras completas, v. 6. São Paulo, Cia das Letras, 2016.

FREUD, S. As pulsões e seus destinos. Trad. Pedro Heliodoro Tavares. Belo Horizonte: Autêntica, 2019.

FROMM, E. Über Methode und Aufgabe einer analytischen Sozialpsychologie. In: Zeitschrift für Sozialforschung. Leipzig (Hirschfeld Verlag), Band I (1932), pp.28-54. Reimpressão: München, DeutscherTaschenbuch Verlag, 1980.

FROMM, E. Die psychoanalytische Charakterologie und ihre Bedeutung für die Sozialpsychologie. In: Zeitschrift für Sozialforschung. Leipzig (Hirschfeld Verlag), Band I (1932), pp.253-237. Reimpressão: München, DeutscherTaschenbuch Verlag, 1980.

FROMM, E. Sozialpsychologischer Teil. In: Horkheimer, M. (Hrgs.). Studien über Autorität und Familie. Forschungsberichte aus dem Institut für Sozialforschung. Schriften des Instituts für Sozialforschung. Fünfter Band. Reprint der Ausgabe Paris 1936. Lüneburg: Dietrich zu Klampen Verlag, 1987.

GAYRAUD, A. Nietzsche: les Lumières et la cruauté. De l'interprétation de Nietzsche par la Théorie critique. Astérion, v.7, 2010. Disponível em: http://asterion.revues.org/1585 Acesso: 05.06.2020.

GENEL, K. Autorité et Émancipation: Horkheimer et la Théorie critique. Paris: Payot, 2013.

HORKHEIMER, M. Authoritarianism and Family Today. In: Anshen, R. (ed.). The family: its function and destiny. New York: Harper \& Brothers, 1949.

HORKHEIMER, M. Gesammelte Schriften. Schmidt, A. und Noerr, G. S. (hrsg.). Frankfurt: Fischer, 1985-.

HORKHEIMER, M. Teoria tradicional e teoria crítica. Trad. Edgard Malagodi e Ronaldo Cunha. In: Benjamin, Walter; Horkheimer, Max; Habermas, Jürgen; Adorno, Theodor. São Paulo: Abril Cultural, 1980.

HORKHEIMER, M. Allgemeiner Teil. In: Horkheimer, M. (Hrgs.). Studien über Autorität und Familie. Forschungsberichte aus dem Institut für Sozialforschung. Schriften des Instituts für Sozialforschung. Fünfter Band. Reprint der Ausgabe Paris 1936. Lüneburg: Dietrich zu Klampen Verlag, 1987. [Trad. bras.: HORKHEIMER, M. Autoridade e família. Trad. Hilde Cohn. In: Teoria crítica I. São Paulo: Perspectiva, 2011.] 
HORKHEIMER, M. Egoismus und Freiheitsbewegung (Zur Anthropologie des bürgerlichen Zeitalters). In: Zeitschrift für Sozialforschung. Paris (Librairie Félix Alcan), Band 5 (1936), pp.161-371. Reimpressão: München, Deutscher Taschenbuch Verlag, 1980.

HORKHEIMER, M. A presente situação da filosofia social e as tarefas de um instituto de pesquisas sociais [1931]. Trad. Carlos Machado e Maria Isabel Loureiro. Praga: estudos marxistas, n.7, 1999, pp.121-132.

HORKHEIMER, M. História e psicologia. Trad. Hilde Cohn. In: Teoria crítica I. São Paulo: Perspectiva, 2011.

HORKHEIMER, M. Da discussão do racionalismo na filosofia contemporânea. Trad. Hilde Cohn. In: Teoria crítica I. São Paulo: Perspectiva, 2011.

HORKHEIMER, M. Materialismo e metafísica. Trad. Hilde Cohn. In: Teoria crítica I. São Paulo: Perspectiva, 2011.

HORKHEIMER, M. Eclipse da razão. Trad. Carlos H. Pissardo. São Paulo: Unesp, 2015.

JAY, M. A imaginação dialética: história da Escola de Frankfurt e do Instituto de pesquisas sociais. Rio de Janeiro: Contraponto, 2008.

LAPLANCHE, J. e PONTALIS, J.-B. Vocabulário da psicanálise. São Paulo: Martins Fontes, 2000.

MARCUSE, H. Eros and Civilization: A Philosophical Inquiry into Freud. Boston: Beacon, 1974.

RAUlET, G. La mort aux deux visages. Sur le statut de l'agressivité et de la pulsion de mort dans Malaise dans la civilisation. In : Rey-Flaud, H. ; Le Rider, J,; Plon, M.; Raulet, G. Autour du Malaise dans la culture de Freud. Paris: PUF, 1998.

ROUANET, S. P. Teoria crítica e psicanálise. Rio de Janeiro; Fortaleza: Tempo Brasileiro; Universidade Federal do Ceará, 1983.

RICKERT, J. The Fromm-Marcuse Debate Revisited. In: Theory and Society, v.15, n.3, May 1986, pp. 351-400. Disponível em: www.jstor.org/stable/657323 Acesso: 10.06.2020.

SOUZA, P. C. de. As palavras de Freud. São Paulo: Cia das letras, 2010.

WHITEBOOK, J. Perversion and Utopia: A Study in Psychoanalysis and Critical Theory. Cambridge, Massachusetts, London: MIT Press, 1995.

WHITEBOOK, J. Freud: An Intellectual Biography. New York: Cambridge University Press, 2017. 